\title{
Involuntary automaticity: a potential legal defence against an allegation of clinical negligence?
}

\author{
B Toft, ${ }^{1}$ P Gooderham ${ }^{2}$
}

\section{See Commentary, p 3 \\ ${ }^{1}$ Faculty of Health \& Life \\ Sciences, Coventry University, Coventry, UK; ${ }^{2}$ Cardiff Law \\ School, Cardiff University, \\ Cardiff, UK}

Correspondence to:

Professor B Toft, 1 Gartons

Road, Middleleaze, Swindon

SN5 5AG, UK;

brian.toft@ntlworld.com

Accepted 2 July 2008

\begin{abstract}
Background: It has been argued that the safety of patients can be put at risk because the verbal challenge-response protocols, frequently used by healthcare professionals - can be compromised by the system of work in use and the operational environment. Individuals who constantly undertake verbal doublechecking safety protocols, when subjected to adverse operational conditions such as high workloads, strict time constraints and high levels of stress, can be captured by a so-called "involuntary automaticity."
\end{abstract}

Conclusion: Evidence suggests that involuntary automaticity could be used as a potential legal defence, against an allegation of clinical negligence, where the healthcare professional concerned had warned their management that the conditions in which they worked could promote the phenomenon, and no remedial actions had been taken by them.

It has been argued by Toft and Mascie-Taylor that the safety of patients can be put at risk because the verbal challenge-response protocols, frequently used by healthcare professionals - can be compromised by the system of work in use and the operational environment. ${ }^{1}$ In their paper it is argued that individuals who constantly undertake verbal double-checking safety protocols, when subjected to adverse operational conditions such as high workloads, strict time constraints and high levels of stress, can be captured by a dysfunctional sociopsychological error promoting phenomenon they have labelled "involuntary automaticity."

Once captured by involuntary automaticity, it is contended that while the individuals undertaking a verbal double-checking safety protocol believe they are concentrating on the task in hand, in reality, only a superficial amount of attention is being paid to the items in the list being checked. Thus, if an error is present in the task being validated, there is a significant risk it can be missed without the individuals carrying out the safety protocol realising it. Clearly, where such a situation exists, there is the potential for a patient to be harmed. A brief overview of a serious patient safety incident where it was argued that involuntary automaticity adversely affected the staff can be found in the box.

\section{CONSCIOUS AUTOMATICITY}

Automaticity arises in human behaviour when skilled activities, such as driving, are practised regularly. Instead of processing the information one step at a time, such as when learning the activity, the cognitive system automatically applies the appropriate rules to the procedure, thus reducing the demands made on working memory. The spare cognitive capacity made available by this process can then be used to process other tasks simultaneously. At this point a person's behaviour can be characterised as having become "automatised." The person is however consciously aware that the skill they are utilising is being controlled in such a way.

\section{INVOLUNTARY AUTOMATICITY}

When discussing the concept of automaticity it is usually the benefits that it brings, such as being able to carry out tasks in parallel, which are debated. ${ }^{2}$ Thus, it is has generally been thought to be a highly desirable characteristic of human cognition. However, there also appear to be costs associated with people being able to enhance their performance by such means. ${ }^{3}$ The potentially dangerous nature of involuntary automaticity arises because there are situations where the cognitive system recognises the task being performed, for example a verbal double-checking safety protocol, and then automatically applies the appropriate rules to that task.

However, on these occasions, Toft and MascieTaylor argue that those affected do not realise that such a process has been activated and therefore may inadvertently miss an error which is present. Consequently, it is possible for those who are carrying out the check to form an erroneous, but firm, belief that the system of work they are about to embark on is safe when in fact it is not. This occurs in part because "... they see what they expect to see rather than what is actually accomplished or indicated." Once established, the flawed belief that has been generated due to involuntary automaticity becomes the checker's "reality," and it is that mistaken conviction which then influences their conscious and deliberate actions. Therefore, although a verbal challengeresponse safety check has been carried out in full, where involuntary automaticity has been induced it may not be effective. ${ }^{5}$

The problem for healthcare professionals arises because if they should miss an error due to involuntary automaticity, and a patient is harmed, then those involved could be the subject of disciplinary or even criminal charges. This raises the prospect that healthcare professionals could in the future and may have in the past been unjustly blamed or found guilty of causing a serious adverse patient safety incident that was not as a result of their negligence. This is because the systems environment in which they worked actively promoted involuntary automaticity, and it is to that which they unconsciously succumbed. 
For example, Lisa Norris, aged 15 years was being treated with radiotherapy for a brain tumour at Glasgow's Beatson Oncology Centre (BOC), Scotland in 2006. As a result of human error, Lisa was inadvertently administered 19 consecutive overdoses of radiotherapy. Following an investigation into the circumstances surrounding her death, the official report published by the Scottish Executive concluded:

\begin{abstract}
.. that most of the responsibility and hence any blame that can be attributed to treatment planning staff at the BOC falls to the staff member referred to in the report as Principal Planner A. ${ }^{6}$
\end{abstract}

Yet the report also came to the conclusion that:

\begin{abstract}
... corporate failings were responsible for creating the conditions under which the mistakes identified in this report were made and that management at all levels must share the blame for these failings. ${ }^{\text {? }}$
\end{abstract}

Thus, although it was explicitly recognised in the report that the management of BOC allowed a situation to develop that was "... not conducive to error-free working," blame was still attributed to the frontline staff involved in the incident, ${ }^{8}$ albeit they appear to have had no option other than to do the best they could under the prevailing circumstances.

It is perhaps interesting to note that the underlying conditions described in the report appear to be similar to those found to promote involuntary automaticity. When this similarity was brought to the attention of the Scottish Executive by the Medical Protection Society, they replied that: "The inspectors' report avoids speculation on psychological factors."

Given that involuntary automaticity is a socio-psychological phenomenon, induced by the environment in which healthcare professionals work, such a standpoint by the Health and Safety Regulator raises an ethical dilemma with regard to justice. For example, if a group of healthcare professionals inform their manager that their working conditions could promote involuntary automaticity, and the manager takes no remedial action because the hazard to be avoided is a sociopsychological state and not a physical one, what then? Should an error be inadvertently missed by the healthcare professionals who warned that involuntary automaticity could occur, and this leads to a patient being seriously harmed, who is responsible: the healthcare professionals who tried to prevent the adverse incident from arising by informing their management that such an adverse event could occur, their management for not attempting to rectify the situation or both? The remainder of this paper is dedicated to discussing this question.

\section{POTENTIAL LEGAL RAMIFICATIONS OF INVOLUNTARY AUTOMATICITY}

Evidence suggests that involuntary automaticity is unconsciously induced in healthcare professionals as a direct result of their system of work and the operating environment. However, it is the managers of healthcare professionals who are directly responsible for the creation of the environment in which healthcare professionals work. Thus, if the manager of a healthcare professional is explicitly warned that the current working environment could lead to their staff being unconsciously captured by involuntary automaticity, and the manager does not implement any remedial actions, then should an error be missed, it could be argued that it is the manager of those healthcare professionals who should be held accountable for the incident and not the healthcare professionals who inadvertently missed the error.

The logic underlying this argument is based upon the principle of justice. It does not appear to be equitable for a healthcare professional to be held legally or professionally accountable for a patient safety incident (PSI) if it occurs under the same or similar circumstances that they warned their manager it might and where the manager took no remedial action. Of course, the manager might argue that the predicted sociopsychological phenomenon was not likely to occur and that the healthcare professional concerned was being overly cautious.

However, where a manager adopts such a position, and the predicted consequence materialises, then the accountability for its occurrence, we argue, should reside with the manager, and not with the healthcare professional who missed the error. This is because the manager, knowing all the facts and having the authority to change the healthcare professional's working environment, has taken a conscious decision to accept the risk of a PSI occurring, whereas, should an error be overlooked by that healthcare professional, this would be an unconscious and involuntary act. Hence, the manager is consciously taking a risk which places the healthcare professional's patients in harm's way by deliberately allowing their staff to work in an environment where it is foreseeable that the operating conditions could promote human error. Moreover, this line of argument could be taken through to the Chief Executive of a Trust and beyond.

This argument based upon justice stands the traditional way of looking at allegations of clinical negligence on its head, for instead of healthcare professionals who inadvertently cause an injury to a patient being held accountable for a PSI, in the circumstances discussed above it would be the "manager" of those healthcare professionals. As Mayles suggests, with regard to the PSI suffered by Lisa Norris, it is:

... those who do not design systems to ensure that independent checks are carried out who are to blame [for the incident] rather than the unfortunate person who makes a mistake under pressure. $^{10}$

The concept of involuntary automaticity as a defence for an individual has considerable consistency with established principles of English civil and criminal law, and, especially, professional ethical guidance. As already noted, a manager's awareness of a risk before an error is made is significant.

\section{CIVIL LAW AND VICARIOUS LIABILITY}

An employer is vicariously liable for the torts (civil wrongs) of his employee carried out in the course of his employment. ${ }^{11}$ Generally, the employee is not wholly insulated from liability, ${ }^{12}$ although usually in practice they will not be sued. The NHS has borne tort liability for the clinical conduct of all of its employees since 1990. In other areas of work, it is possible for the employee to remain liable-for example, if the employer is insolvent. ${ }^{13}$ The concept of involuntary automaticity suggests that the employee who has warned their management that there is a significant potential for error due to the system of work in place is not morally culpable, and that the fault lies with the employer, who is then liable via a direct duty of care. This is in keeping with the current arrangement in the NHS, in which NHS bodies such as hospital trusts have primary liability to patients. 
It seems that the key difference offered by a concept of involuntary automaticity is to give greater protection to the employee from liability. A successful clinical negligence claim must of course satisfy the tests for professional negligence set in Bolam and Bolitho. ${ }^{14}{ }^{15}$ An individual professional defendant will not be negligent if they have acted in accordance with a responsible body of professional opinion (Bolam), subject to the additional requirement of Bolitho that the opinion is capable of withstanding logical analysis.

Therefore, a health professional who has acted in a reasonable and rational way, intending to prevent an error occurring, is unlikely to be found to be negligent using Bolam/Bolitho. A person in a managerial role, who has received information about a potential risk and failed to respond reasonably, may, however, fail the Bolam/Bolitho test.

The importance attached to a managers' awareness of a potentially unsafe system of work is familiar to tort lawyers, as it influences what is reasonably foreseeable. ${ }^{16}$

\section{CRIMINAL LAW}

Criminal liability classically requires actus reus (the "guilty act"), mens rea (the "guilty mind") and the absence of a defence. Mens rea for more serious offences is usually intention or recklessness. It follows that a defendant who did not intend the prohibited outcome of his conduct, and did not perceive the risk of such an outcome, like someone acting automatically, will not be liable for such offences.

Many offences, however, do not require mens rea; these include negligence-based offences. Criminal negligence is variously defined. One definition is "... the inadvertent taking of an unjustifiable risk." ${ }^{17}$ Allen notes that negligence is not really a state of mens rea because it is inadvertent, although it is a type of legal fault. ${ }^{18}$ Other definitions use the concept, familiar from tort law, of falling below a reasonable standard of conduct. Card, for example, states:

A defendant is negligent as to a consequence of an act or omission on his part if:

The risk of it occurring would have been foreseen by a reasonable person and

The defendant either fails to foresee the risk and to take steps to avoid it or having foreseen it, fails to take steps to avoid it or takes steps which fall below the standard of conduct which would be expected of a reasonable person in the light of that risk. ${ }^{19}$

It will be seen that because criminal negligence may be inadvertent, liability may arise without mens rea. Involuntary automaticity is therefore not itself a complete defence against criminal negligence. Involuntary automaticity is not the same as the rare criminal defence of automatism, which requires a total loss of voluntary control caused by an external factor, and that the defendant must not be at fault in losing capacity. ${ }^{20}$ However, involuntary automaticity, as evidence of an unsafe system, might well influence a jury in a case of gross negligence manslaughter, and could conceivably reduce the likelihood of a prosecution being brought.

The leading case in gross negligence manslaughter is Adomako. ${ }^{21}$ The defendant, whose conviction was upheld, was an anaesthetist whose patient died after he had failed to notice interruption of the oxygen supply. There were some adverse situational factors. Dr Adomako had taken over the procedure from another anaesthetist, he had had very little sleep after being on call at another hospital, and he did not have the assistant he was supposed to have. In such circumstances if, as seems likely, such factors increase the risk of error, there is a case for making the employers liable.

Following the cases of Adomako and Misra, a conviction for gross negligence manslaughter requires the existence of a duty of care, breach of that duty resulting in death and a risk of death which would be obvious to a reasonable prudent person. ${ }^{22}$ Additionally, and importantly, the defendant's conduct must have fallen so far below the standard of a reasonable practitioner as to be grossly negligent in the view of the jury, and thereby warranting a criminal conviction for manslaughter. It will be noted that the existence of a prior warning from the defendant (or anyone else) about a potentially unsafe system of work, such as involuntary automaticity, might be powerful evidence which could influence a jury towards a decision to acquit the individual defendant, although his own conduct will remain highly relevant.

Generally in the criminal law, an employer does not have vicarious liability for the criminal conduct of an employee. However, a corporate body may itself be liable for crime. At common law, for a corporate body to be criminally liable, it is necessary to identify a "controlling mind" among the directors, an individual whose own conduct makes them liable personally. ${ }^{23}$ This "identification principle" means that generally, only small companies have been convicted. The Corporate Manslaughter and Corporate Homicide Act 2007 came into force on 6 April 2008 and should make prosecutions of corporate bodies for manslaughter more easy. ${ }^{24}$ It will apply to the NHS. The act retains the requirement of death caused by gross breach of duty of care. Section 1(3) provides that:

\section{An organisation is guilty of an offence under this section only if the way in which its activities are managed or organised by its senior management is a substantial element in the breach ...}

Under section 8 of this Act, the jury may consider evidence that there were "attitudes, policies, systems or accepted practices within the organisation" which are likely to have encouraged failure to comply with health and safety legislation relevant to the breach of duty of care, or to have produced tolerance of it. This might include failure to address a system of work thought to have been unsafe, including systems giving rise to involuntary automaticity.

Other criminal sanctions may be applied to employers. In Misra, two junior doctors were convicted of gross negligence manslaughter after a patient died of a postoperative infection which they failed to diagnose. Additionally, Southampton University Hospital NHS Trust in the UK where they were employed was successfully prosecuted under section 3(1) of the Health and Safety at Work Act 1974. This provides:

General duties of employers and self-employed to persons other than their employees

(1) It shall be the duty of every employer to conduct his undertaking in such a way as to ensure, so far as is reasonably practicable, that persons not in his employment who may be affected thereby are not thereby exposed to risks to their health or safety.

The Trust was fined $£ 100000$ (reduced to $£ 40000$ on appeal). ${ }^{25}$ The initial charge had included allegations of failing to take up a reference for one of the doctors, failing to implement a system of ward rounds, failing to have proper hand-over meetings for staff in the department and not having a policy of encouraging nursing staff to report concerns about patients. Ultimately the Trust pleaded guilty to an amended 
charge that concentrated only on the inadequate supervision of the doctors in the trauma and orthopaedic department. ${ }^{26}$

A key feature of the Southampton case was that criticisms of the management of the junior orthopaedic doctors had been made by a nurse specialist in the department and by the Commission for Health Improvement, although it is not clear from the reported chronology in the law report that these were received before the death of the patient. While this episode is not one in which involuntary automaticity is an issue, it does illustrate an unsafe system of work about which warnings existed, and it is a disaster following which individual defendants were convicted, even though serious management failures were identified.

However, if a healthcare professional were to argue that involuntary automaticity was the cause of the PSI in which they were involved, an employer might find it far more difficult to defend a prosecution under the Health and Safety at Work Act 1974 and the Corporate Manslaughter and Corporate Homicide Act 2007 if warnings had earlier been given concerning systems of work where the risk of such an error being made had been identified. In such circumstances, the relative punishments administered to individuals and their managers by the Courts could be a reversal of those noted earlier in Adomako and Misra.

\section{PROFESSIONAL ETHICS AND DISCIPLINE}

Medical professional guidance from the General Medical Council (GMC) is clear about the duty to warn of potentially unsafe systems. This is because a doctor may be personally liable for mistakes made in clinical practice, and may have a duty to report any perceived potential for error arising from systems in which they work. It may also be that doctors in management roles may be accountable to the GMC for inadequate response when such issues are raised. ${ }^{27}$

In Good Medical Practice, the GMC includes a requirement of doctors to rectify, if possible, systems which may seriously compromise patient safety. If this is not possible, they should notify the matter to the employer or contracting body. ${ }^{28}$

In Management for Doctors, the GMC states that a doctor in a managerial role has a duty of care for the safety and well-being of patients, and retains accountability to the GMC. ${ }^{29}$

\section{Box Example of involuntary automaticity}

- Part of the treatment regime prescribed for a patient about to undergo radiotherapy was that a radiation attenuation device known as a "wedge" be placed in one of the treatment beams. However, this parameter was not entered into the computer database that controls the Linear Accelerator (Linac), which delivers the treatment beams. As a result, the patient was administered an overdose of radiation on 14 of the 15 individual treatments prescribed by the consultant before the error was discovered. It was calculated that the patient had been inadvertently administered 2.5 times the total dose of radiotherapy that had been prescribed.

- The erroneous treatment was inadvertently administered by 12 different dedicated radiographers working in assorted pairs and using a verbal double checking safety protocol. However, on each occasion that the patient was administered radiotherapy, the two radiographers treating the patient failed to perceive that the wedge field of the Linac console displayed the word "OUT" instead of the word "IN."
The GMC also stipulates that doctors in managerial roles should do their best to ensure that:

\begin{abstract}
significant risks to patients, staff and the health of the wider community are identified, assessed and addressed to minimise risk, and that they are reported in line with local and national procedures. ${ }^{30}$
\end{abstract}

Recognition of involuntary automaticity as an unsafe system of work suggests that doctors have a professional duty to address and rectify it. Demonstrable compliance with this professional guidance should protect against disciplinary sanctions. It should also be highly persuasive in favour of individuals who are defendants in civil and criminal litigation.

\section{DISCLOSURE AND LITIGATION}

For a prior warning of a potentially unsafe system to operate as a defence for an individual defendant, it must be known to exist. Usually the defendant seeking to use it will know of it, but this may not be so. The duty of disclosure on parties to litigation is well established, ${ }^{31}$ but apparent failure to comply has featured in notable miscarriages of justice (a notable example being $R \vee C l a r k^{32}$ ) and may itself lead to professional disciplinary proceedings and other investigations (see, for example, Gooderham ${ }^{33}$ ). It follows that the recipient of any warning of an unsafe system, and parties to litigation who receive evidence that a warning was made, must understand their duty to disclose it.

\section{CONCLUSIONS}

There is evidence to suggest that involuntary automaticity is an error-forcing phenomenon with great relevance to incidents in healthcare. Hence, where a warning is given that the environment in which healthcare professionals work could promote involuntary automaticity, it is likely to heighten the legal and professional liability of those in managerial roles. Moreover,it presents the opportunity for a healthcare professional who is prosecuted, and their lawyers, to place important evidence in their defence before the court.

In essence, the evidence suggests that involuntary automaticity could be used as a potential legal defence, against an allegation of clinical negligence, where the healthcare professional concerned had warned their management that the conditions in which they worked could promote the phenomenon, and no remedial actions had been taken by them.

Competing interests: None.

\section{REFERENCES}

1. Toft B, Mascie-Taylor H. Involuntary automaticity: a work-system induced risk to safe health care. Health Serv Manage Res 2005;18:211-16.

2. Barshi I, Healy A. Checklist procedures and the cost of automaticity. Mem Cognit 1993;21:496-505.

3. Reason J. Actions not as planned: the price of automatization. In: Underwood G, Stevens R, eds. Aspects of consciousness. London: Academic Press, 1979:67-88.

4. Office of Safety Services, Safety Analysis Division. Human performance considerations in the use and design of aircraft checklists. Washington: US Department of Transportation Federal Aviation Administration, 1995:43. http://www. faa.gov/about/office_org/headquarters_offices/avs/offices/afs/afs200/branches/ afs210/training_aids/media/checklist.doc (accessed 16 Oct 2008).

5. French J. Treatment errors in radiation therapy. Radiat Ther 2002;11:149-58.

6. Johnston AM. Unintended overexposure of patient Lisa Norris during radiotherapy treatment at the Beatson Oncology Centre, Glasgow in January 2006, Report of an investigation by the Inspector appointed by the Scottish Ministers for The lonising Radiation (Medical Exposures) Regulations 2000: iii. Edinburgh: Scottish Executive, 2006. http://www.scotland.gov.uk/Resource/Doc/153082/0041158.pdf laccessed 16 October 2008).

7. Johnston AM. Unintended overexposure of patient Lisa Norris during radiotherapy treatment at the Beatson Oncology Centre, Glasgow in January 2006, Report of an 
investigation by the Inspector appointed by the Scottish Ministers for The lonising Radiation (Medical Exposures) Regulations 2000: section 10.18, 46. Edinburgh: Scottish Executive, 2006. http://www.scotland.gov.uk/Resource/Doc/153082/ 0041158.pdf (accessed 16 October 2008).

8. Johnston AM. Unintended overexposure of patient Lisa Norris during radiotherapy treatment at the Beatson Oncology Centre, Glasgow in January 2006, Report of an investigation by the Inspector appointed by the Scottish Ministers for The lonising Radiation (Medical Exposures) Regulations 2000: section 10.1, 43. Edinburgh: Scottish Executive, 2006. http://www.scotland.gov.uk/Resource/Doc/153082/ 0041158.pdf (accessed 16 October 2008).

9. Williams, S. What did you just do? Casebook (Medical Protection Society) 2007:15:12-14

10. Mayles, WPM. The Glasgow incident-a physicist's reflections. Clin Oncol 2007:19:4-7.

11. Lister v Hesley Hall. 1 AC 215 (2002)

12. Standard Chartered Bank v Pakistan National Shipping Corporation. UKHL 43 (2002).

13. Merrett v Babb. 3 WLR 1 (2001).

14. Bolam v Friern Hospital Management Committee. 1 WLR 582 (1957).

15. Bolitho $v$ City and Hackney Health Authority. AC 232 (1998).

16. Walker v Northumberland County Council. All ER 737 (1995).

17. Ormerod D. Smith \& Hogan's criminal law. 11th edn. Oxford: Oxford University Press, 2005:109.

18. Allen M. Textbook on criminal law. 8th edn. Oxford: Oxford University Press, 2005.

19. Card R. Card, Cross \& Jones' criminal law. 17th edn. Oxford: Oxford University Press, 2006, para 3.33 .
20. $R v$ Quick. OB 910 (1973).

21. $R$ v Adomako. 1 AC 171 (1995).

22. $R$ v Misra, $R$ v Srivastava. EWCA Crim. 2375 (2004).

23. Attorney General's Reference No. 2 of 1999. QB 796 (2000).

24. Anon. Corporate Manslaughter and Corporate Homicide Act 2007. http://www.opsi. gov.uk/acts/acts2007/20070019.htm (accessed 12 May 2008).

25. $R v$ Southampton University Hospital NHS Trust. EWCA Crim. 2971 (2006).

26. British Broadcasting Corporation. Trust guilty over death doctors. http://news. bbc.co.uk/1/hi/england/hampshire/4602228.stm (accessed 21 Oct 2008).

27. Roylance v General Medical Council. 1 AC 311 (2000).

28. General Medical Council. Good medical practice, 2006. http://www.gmc-uk.org/ guidance/good_medical_practice/good_clinical_care/raising_concerns.asp para 6 (accessed $21 \overline{0}$ ct 2008).

29. General Medical Council. Management for doctors, para 4, 2006. http://www. gmc-uk.org/guidance/current/library/management for doctors.asp laccessed 21 0ct 2008).

30. General Medical Council. Management for doctors, para 12, 2006. http://www. gmc-uk.org/guidance/current/library/management for doctors.asp (accessed 12 May 2008.

31. Anon. Part 31 of the Civil Procedure Rules. Criminal Procedure and Investigations Act 1996, sections 3, 4 and 7A http://www.justice.gov.uk/civil/procrules fin/contents/ parts/part31.htm (accessed 21 Oct 2008).

32. $R$ v Clark. EWCA Crim 1020 (2003).

33. Gooderham, P. Expert evidence assessed_again 2007 March. New Law J 157:341

\section{Keep up to date: sign up for our alerting services}

Find out automatically when an article is published on a specific topic or by a particular author. We can also alert you when an article is cited or if an eLetter or correction is published. You can also choose to be alerted when a new issue is published online [and when we post articles Online First]. Check out the New Content Alerts and Citation tracker from the Online tools section on the home page. 


\section{Involuntary automaticity: a potential legal defence against an allegation of clinical negligence?}

B Toft and P Gooderham

Qual Saf Health Care 2009 18: 69-73

doi: 10.1136/qshc.2007.024273

Updated information and services can be found at:

http://qualitysafety.bmj.com/content/18/1/69.full.html

These include:

References This article cites 5 articles, 1 of which can be accessed free at: http://qualitysafety.bmj.com/content/18/1/69.full.html\#ref-list-1

Article cited in:

http://qualitysafety.bmj.com/content/18/1/69.full.html\#related-urls

Email alerting

Receive free email alerts when new articles cite this article. Sign up in the box at the top right corner of the online article.

Notes

To request permissions go to:

http://group.bmj.com/group/rights-licensing/permissions

To order reprints go to:

http://journals.bmj.com/cgi/reprintform

To subscribe to BMJ go to:

http://group.bmj.com/subscribe/ 